\title{
Evaluation of the Thermodynamic Properties of Air Cycle Refrigeration System
}

\author{
Ujam Amechi Joseph, Onovoh Johnpaul Nkemjika, \\ Department of Mechanical Engineering, \\ Nnamdi Azikiwe University, \\ Awka, Nigeria.
}

\begin{abstract}
The effects of possible parameters affecting system performance air cycle refrigeration systems are examined through analysis of the thermodynamic properties. The study was carried out on varying number of air cycle refrigeration system used in air conditioning the cabin of an aircraft. Analysis was carried out for each of the system types to determine some parameters as cabin temperature $\left(T_{c b}\right)$, Refrigerating effect $(R E)$, compressor work $\left(W_{c}\right)$ and coefficient of performance (COP) from the evaluated parameters. Results show that Bootstrap Air Cycle Refrigeration System has the best COP of 0.78 followed by the system working on reversed joule cycle (Bell-Coleman cycle) with COP of 0.68, while the Reduced Ambient Air Cycle Refrigeration System produced the best refrigerating air temperature of $245.56 \mathrm{~K}\left(-27.44^{\circ} \mathrm{C}\right)$ at entropy of $1.029127 \mathrm{~kJ} / \mathrm{kgK}$ that necessitated the cooling of the cabin from a temperature of $323 \mathrm{~K}\left(50^{\circ} \mathrm{C}\right)$ to $294 \mathrm{~K}\left(21^{\circ} \mathrm{C}\right)$. This is required comfort temperature for the cabin occupants. These have a whole lot of similarity with functioning data designed originally for the ACRSs meant for trains. Response surface methodology was done using Design Expert V11 (Trial Version) for optimization. The thermodynamic properties so determined in this study will be useful in designing Nigerian made aircraft and also serves as an important addition to the information storage bank of research institutes in the country.
\end{abstract}

Keywords--- Refrigerating effects; compressor work; coefficient of performance; temperature; response surface methodology.

\section{INTRODUCTION}

In explaining refrigeration, it can be said to be a process of removing heat from an enclosed space or from a substance for the purpose of lowering the temperature. The flow of heat is in the direction of decreasing temperature, which is from high temperature areas to low temperature areas [1]. Reversed Carnot cycle can be use to demonstrate an ideal refrigerator which heat is taken in from a constant low temperature source at $\mathrm{T}_{\mathrm{L}}$ and is given out to a constant high temperature sink $\mathrm{T}_{\mathrm{H}}$. Refrigeration in essence satisfies only one of the four requirements of the air conditioning, i.e. provision of lower temperature than the outdoor surroundings [2]. Air cycle refrigeration system (ACRS) is a gas cycle designed for the comfort of passengers in aircraft cabin as regards to this study. When the working fluid is a gas that is compressed and expanded but doesn't change phase, the refrigeration cycle is seen as a gas cycle [3]. Air is most often this working fluid. As there is no condensation and evaporation intended in a gas cycle, components corresponding to the condenser and evaporator in a vapour compression cycle are the hot and cold gas to gas heat exchangers in gas cycles. The air cycle is less efficient than the vapour compression cycle because the air cycle works on the reverse Brayton cycle instead of the reversed Rankine cycle [4].

For the purpose of this study, we will consider Air-cycle refrigeration system as it relates to the cabin of an aircraft. Air does not undergo any phase change during the cycle; consequently, all the internal heat transfer processes are sensible heat transfer processes.

The significance of this research is to provide a dependable refrigerating property value of the ACRSs used which would be needed for the design of Nigerian customized ACRS considering the environmental factors. One main part of this study is resource evaluation and quantification as regards to refrigerating temperatures, coefficient of performance and thermal efficiency of ACRS.

Air-cycle refrigeration system is widely used in some cold storage room, some industrial or commercial cooling towers, ship's cabins and aircraft's cabins. For the purpose of this work, the analysis is basically for aircraft with a full passengers load and full crew within some 15 windows and $11 \%$ electrical load that flies at the speed of $10 \mathrm{~km} / \mathrm{min}$ at the altitude of $10 \mathrm{~km}$. The thermodynamic properties of the air at the altitude include $0.2650 \mathrm{bar}$ for pressure, $-49.85^{\circ} \mathrm{C}$ for temperature, $0.4134 \mathrm{~kg} / \mathrm{m}^{3}$ for density. This study excludes aircraft meant for wars, jets, and rockets etc. that travel at a very high speed. 


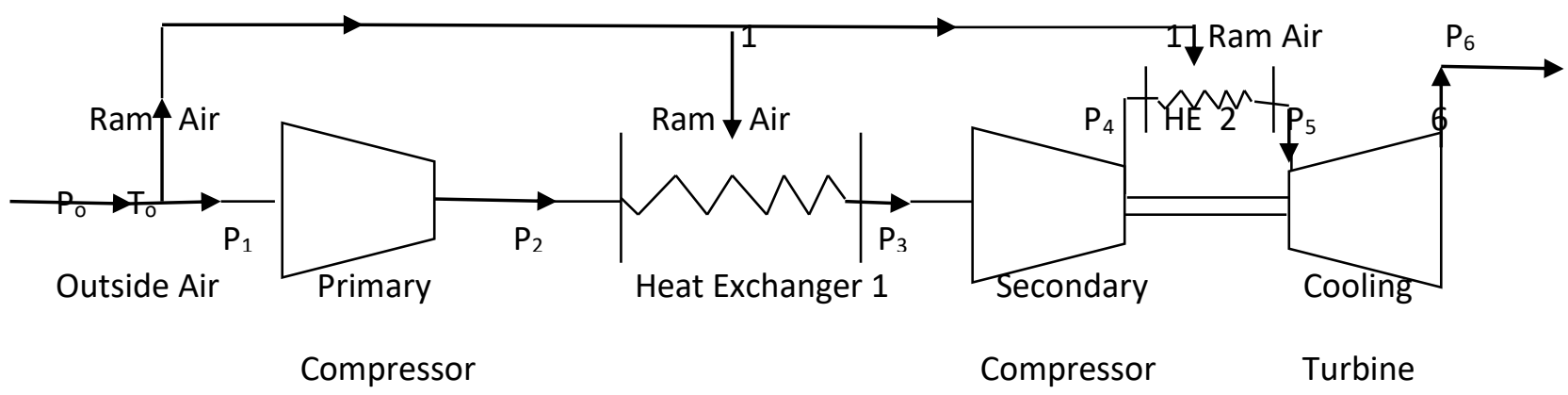

Figure 1: Bootstrap Air Cycle Refrigeration System [5]

\section{MATERIAL AND METHODS}

Akanu Ibiam International Airport (AIIA) Enugu (ENU for IATA) Flight test facility was used for this study. The airlines used for the purpose of this study operate Akanu Ibiam International Airport (AIIA) Enugu (ENU for IATA). Dana airline (DAN for ICAO and AJ for IATA) and Discovery airline (DCV for ICAO and DO for IATA) and Arik airline (ARA for ICAO and W3 for IATA) were used. Six (6) air cycle refrigeration systems were all captured in different aircrafts which might be from the same airline as the case may be. The thermodynamic properties of the ACRS used in the aircraft were measured and sourced from the airline operatives. Except for Basic Air Cycle Refrigeration System with Evaporative Cooling of 2005 model seen in Discovery airline, every other ACRS in Dana and Arik airlines are of newer model (2009-2013). Reduced Ambient Air Cycle Refrigeration System, Regenerative Air Cycle Refrigeration System and Bootstrap Air Cycle Refrigeration System were studied from aircrafts under Dana airlines. Bell Coleman Cycle (System Working on Reversed Joule Cycle) and Basic Air Cycle Refrigeration System without Evaporative Cooling were installed in aircrafts under Arik airlines. However, the practical development of these thermodynamic properties was with the aid of measuring instruments. The measurements were performed continuously from the boarding (starting) time to the flight time. The measured data consisted of temperature, relative humidity and absolute pressure. The measured positions were mostly outside and ram air condition. The instruments used for measurement were the P-RH-T101 data recording instruments produced by Madgetech, an American company and the T-RH-P recording instruments produced by Qingsheng, a Chinese company. The instruments were placed in such a way that the sensor reads the average outside air condition at every altitude. These airlines have an air operator certificate issued by the civil aviation authority of Nigeria, (CAAN). The efficiencies of the compressors and turbines recorded were the ones generally used by the manufacturers of these aircrafts.

\section{A. Evaluation of Temperature and Pressure at different Process}

The relationship between the temperature and pressure at different processes are presented below are as follows

Take $\eta_{c a}=$ Efficiency of auxiliary compressor, $\eta_{t}=$ Efficiency of turbine/expander, $T_{o}$ as Temperature of outside air, $P_{o}$ as Pressure of the outside air, $\mathrm{P}_{1}$ as Pressure of the air after ramming, $\mathrm{P}_{2}$ as Pressure of the air leaving the compressor, $\mathrm{P}_{\mathrm{c}}$ as Cabin pressure (bar), $T_{c}$ as Temperature of the cabin, $T_{2}$ as Temperature of the leaving the compressor, $T_{3}$ as Temperature of the air passed through the heat exchanger. All temperatures are in Kelvin and all pressures in bar.

Ramming action

$$
\mathrm{T}_{1}=\mathrm{T}_{\mathrm{o}}\left(\frac{\mathrm{P}_{1}}{\mathrm{P}_{\mathrm{o}}}\right)^{\frac{\gamma-1}{\gamma}}
$$

Process 1-2 (Compression process)

$$
\mathrm{T}_{2}=\mathrm{T}_{1}\left(\frac{\mathrm{P}_{2}}{\mathrm{P}_{1}}\right)^{\frac{\gamma-1}{\gamma}}
$$

Process 2-3 (Condenser)

Temperature of air entering the expander at constant pressure is $50^{\circ} \mathrm{C}$

Process 3-4 (Expansion process)

$$
\frac{\mathrm{T}_{3}}{\mathrm{~T}_{4}}=\left(\frac{\mathrm{P}_{3}}{\mathrm{P}_{4}}\right)^{\frac{\gamma-1}{\gamma}}
$$

Where $\mathrm{T}_{4}$ and $\mathrm{P}_{4}$ are temperature and pressure entering the aircraft's cabin

Process $3-4^{1}$ (Secondary compression process)

$$
\mathrm{T}_{4^{1}}=\mathrm{T}_{3}\left(\frac{\mathrm{P}_{4}}{\mathrm{P}_{2}}\right)^{\frac{\gamma-1}{\gamma}}
$$

N/B: Discharge pressure $\left(\mathrm{P}_{4}\right)$ of the air from the auxiliary compressor for Bootstrap air cycle refrigeration system $=12 \mathrm{bar}$ 
Process 4-5 (Heat exchanger)

$$
\eta_{\mathrm{ca}}=\frac{\mathrm{T}_{4}{ }^{1}-\mathrm{T}_{3}}{\mathrm{~T}_{4}-\mathrm{T}_{3}}
$$

$$
\mathrm{T}_{5}=\mathrm{T}_{4}\left(1-\varepsilon_{2}\right)+\mathrm{T}_{1} \varepsilon_{2}
$$

Process 5-6 (Expansion process)

$$
\begin{aligned}
\frac{\mathrm{T}_{61}}{\mathrm{~T}_{5}} & =\left(\frac{\mathrm{P}_{\mathrm{c}}}{\mathrm{P}_{4}}\right)^{\frac{\gamma-1}{\gamma}} \\
\eta_{\mathrm{t}} & =\frac{\mathrm{T}_{6}-\mathrm{T}_{5}}{\mathrm{~T}_{6^{1}}-\mathrm{T}_{5}}
\end{aligned}
$$

Work of compression $\left(\mathrm{W}_{\mathrm{c}}\right)=\mathrm{C}_{\mathrm{P}}\left(\mathrm{T}_{2}-\mathrm{T}_{1}\right)$

Coefficient of performance (COP)

$$
\mathrm{COP}=\frac{\text { Refrigerating effect }}{\text { Work of compression }}=\frac{\mathrm{RE}}{\mathrm{W}_{\mathrm{c}}}
$$

\section{B. The Central Composite Design (CCD) of the thermal properties of Air cycle Refrigeration system}

Version 11 CCD of response surface methodology (RSM) of Design Expert software was implemented in this study to design the experiment/optimization of the thermal properties of Air cycle Refrigeration system. The thermal properties were predicted using Central Composite Design (CCD). This was done to determine the best conditions for refrigeration in a cabin system. Also, this helps to examine the interactive effects of the three factors considered. In this study, the factors considered were air temperature $(\mathrm{K})$, work of compression $(\mathrm{kJ} / \mathrm{kg})$ and refrigerating effect $(\mathrm{kJ} / \mathrm{kg})$ as independent variables while the coefficient of performance and entropy $(\mathrm{kJ} / \mathrm{kgK})$ were the dependent variables or responses. CCD involves varying the independent variables at five different levels $(-\mathrm{a},-1,0,+1,+\mathrm{a})$. In this work, a set of 20 experiments were performed which consist of 8 factorial points, 6 centre points and 6 axial points. Moreover, this is because the replicates of factorial points and the replicates of axial points were two to increase the accuracy of the experiment and were performed in a randomized order. The range and levels of all individual variables used are given in Table 1. It is noteworthy to know that the optimal values of the test variables were first obtained in coded units and then converted to the uncoded units. The empirical equation is represented as shown below,

$$
A=\mu_{0}+\sum_{i=1}^{2} \mu_{i} x_{i}+\sum_{i=1}^{2} \mu_{i i} x_{i}^{2}+\sum_{i=j}^{2} \mu_{i j} x_{i} x_{j}
$$

The regression analysis was performed to estimate the response function as a quadratic or second order polynomial: The importance of each term in the equation is to estimate the goodness of fit in each case. Response surfaces were drawn to determine the individual and interactive effects of the test variable on the coefficient of performance and entropy.

Table 1: Factors levels of independent variables in actual and coded form for COP and Entropy.

\begin{tabular}{|l|l|l|r|l|l|r|r|}
\hline Factor Name & Units & $\begin{array}{c}\text { Min. } \\
(-\mathbf{a})\end{array}$ & $\begin{array}{c}\text { Max.(+ } \\
\text { a) }\end{array}$ & \multicolumn{1}{|c|}{ Low(-1) } & High(+1) & $\begin{array}{c}\text { Mean (0 } \\
\text { Level) }\end{array}$ & Std. Dev. \\
\hline $\begin{array}{l}\text { Air } \\
\text { Temperature(A) }\end{array}$ & $\mathrm{K}$ & 232.15 & 248.96 & $-1 \leftrightarrow 235.56$ & $+1 \leftrightarrow 245.56$ & 240.56 & 4.48 \\
\hline $\begin{array}{l}\text { Refrigerating } \\
\text { Effect (B) }\end{array}$ & $\mathrm{kJ} / \mathrm{kg}$ & 74.42 & 91.23 & $-1 \leftrightarrow 77.83$ & $+1 \leftrightarrow 87.83$ & 82.83 & 4.48 \\
\hline $\begin{array}{l}\text { Work of } \\
\text { Compression (C) }\end{array}$ & $\mathrm{kJ} / \mathrm{kg}$ & 176.72 & 178.41 & $-1 \leftrightarrow 177.07$ & $+1 \leftrightarrow 178.07$ & 177.57 & 0.4491 \\
\hline
\end{tabular}

\section{A. Thermal Properties of ACRS}

\section{RESULTS AND DISCUSSION}

For each Air cycle refrigeration system, results were presented from the ambient condition of the air (ramming action). Temperature of air (refrigerant) that goes into the cabin $\left(\mathrm{T}_{\mathrm{cb}}\right)$ was deduced, so also the Refrigerating effect (RE), Work of compression $\left(\mathrm{W}_{\mathrm{C}}\right)$ and the Coefficient of performance $(\mathrm{COP})$ of the system. Plot was made to show the relationship between the ultimate Temperatures versus Entropies. Also the results obtained from the air cycle refrigeration systems showing the temperatures and pressures at every process were reported. In this research, it was also noticed that Bootstrap air cycle refrigeration system has the best COP of 0.78 , followed by the system working on reversed joule cycle (Bell- Coleman cycle with COP of 0.68. Reduced Ambient air refrigeration system has the least COP of 0.45. 


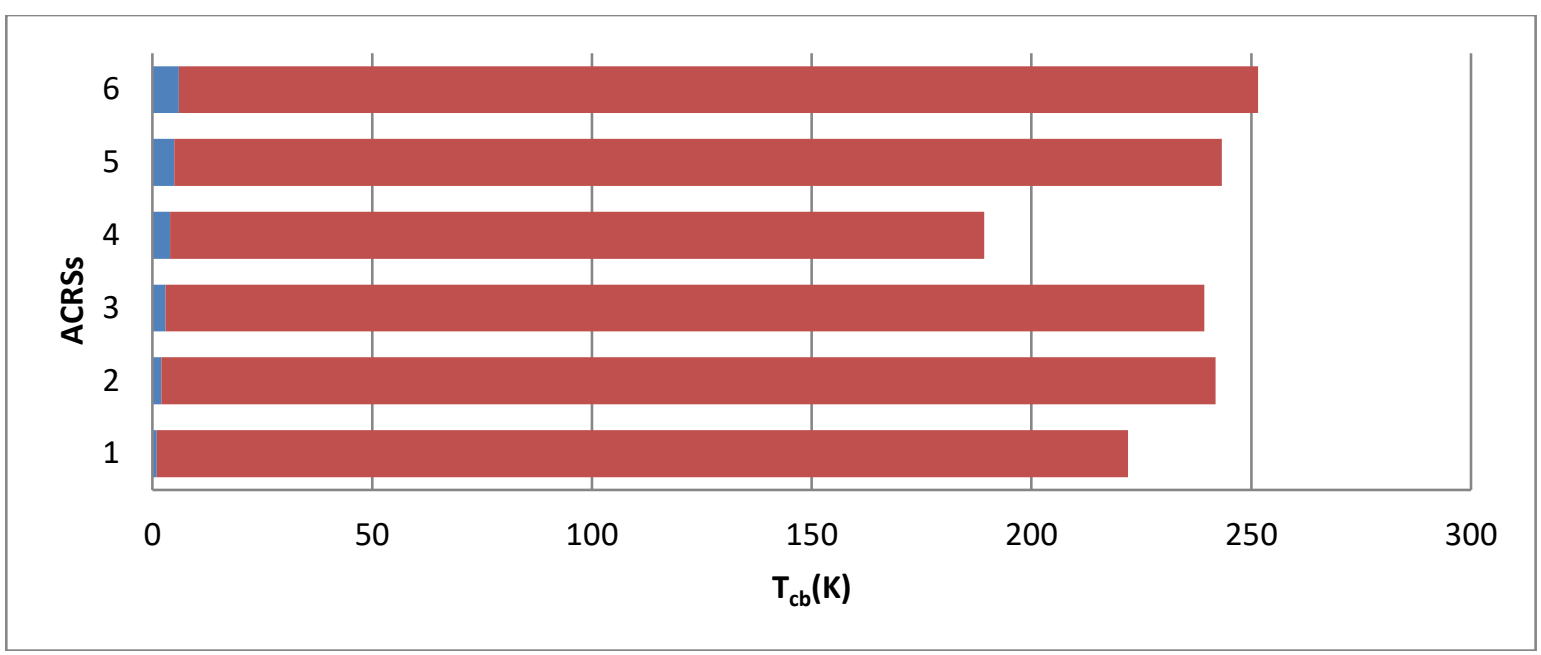

Where

Figure 2: Bar chart showing Air Temperature output of ACRSs

1. System working on reversed Joule cycle (Bell- Coleman cycle), 2. Basic air cycle refrigeration system without evaporative cooling, 3. Basic air cycle refrigeration system with evaporative cooling, 4. Bootstrap air cycle refrigeration system, 5. Regenerative air cycle refrigeration system and $\mathbf{6}$. Reduced ambient air cycle refrigeration system.

Figure 2 shows the difference in the temperatures obtained in all the ACRSs. This temperature is what balances the high temperature produced in the cabin of the aircraft by loads, passengers, electrical gadgets etc. The lower the temperature the more efficient and proficient outputs it yields. In the bar chart above, bar 4 which is the Bootstrap air cycle refrigeration system with temperature of $185.29 \mathrm{~K}$ has the lowest temperature followed by the first bar which is Bell-Coleman cycle. This is because the two ACRSs is widely used for aircrafts with smaller cabin. The ACRS with highest temperature is at sixth bar (Reduced ambient air cycle refrigeration system with largest temperature of $245.56 \mathrm{~K})$.

T-S diagram for Bell- Coleman cycle system is shown in figure 3 below. This was done at the critical conditions of $-140.65^{\circ} \mathrm{C}$ and 37.7436 band showed an elaborate view that included enthalpy in $\mathrm{kJ} / \mathrm{kg}$ and specific volume in $\mathrm{m}^{3} / \mathrm{kg}$. At its ACRS temperature of $-192.55^{\circ} \mathrm{C}$, the entropy extended from $80 \mathrm{~J} / \mathrm{kgK}$ to $2650 \mathrm{~J} / \mathrm{kgK}$. It also indicated enthalpy state from $110 \mathrm{~kJ} / \mathrm{kg}$ and specific volume from 0.005 to $0.1 \mathrm{~m} 3 / \mathrm{kg}$. The enthalpy reflects similar range in its pressure-enthalpy plot. Reference [4] reported similar trend in the uses of Bell Coleman refrigeration system for air conditioning where the expanded air temperature is $289 \mathrm{~K}$ and constant entropy from process 3 to 4 .

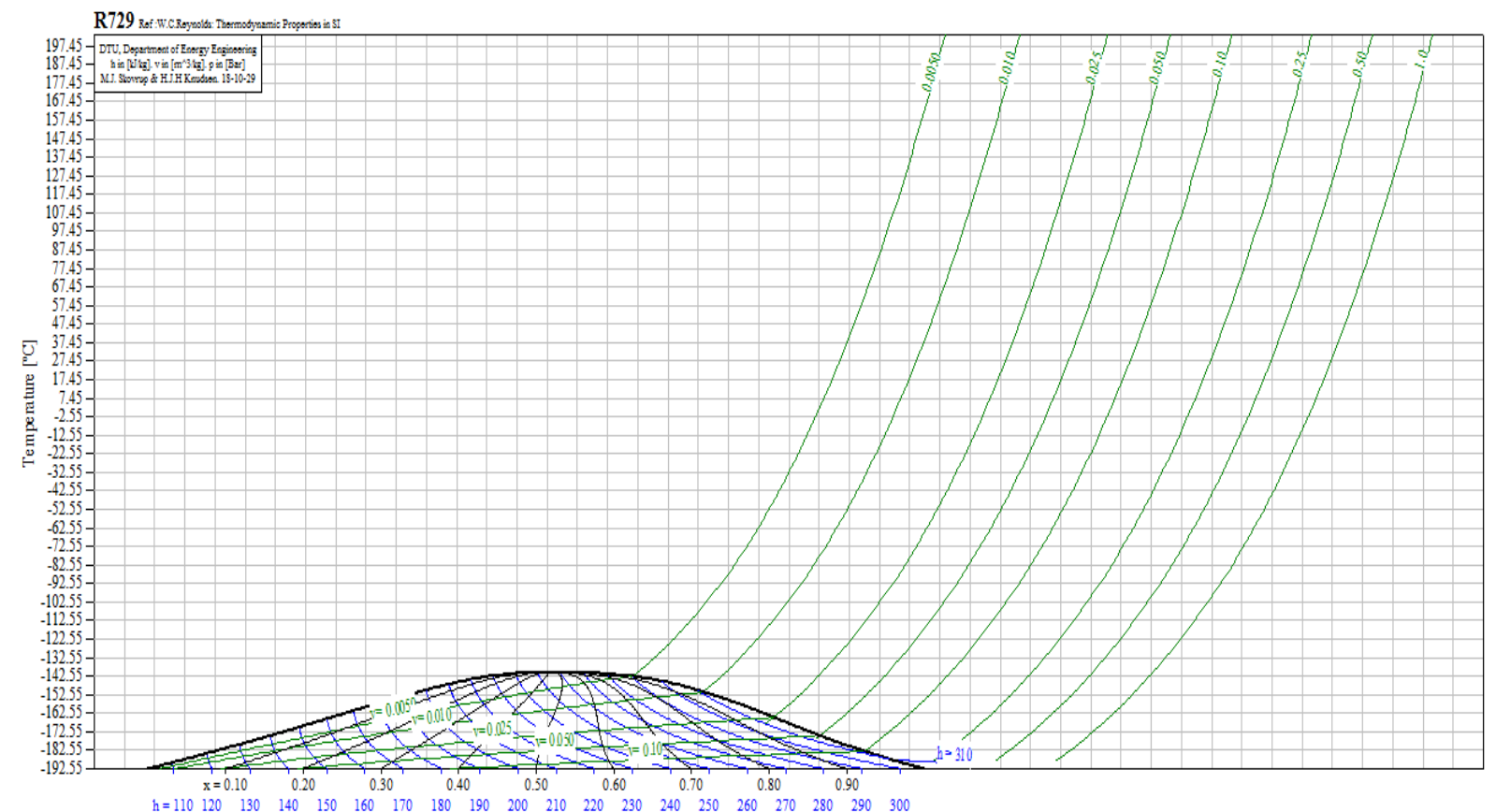

$-1000100200300400500600700800900100011001200130014001500160017001800190020002100220023002400250026002700280029003000310032003300340035003600370038003900400041004200430044004500$ Entropy $[\mathrm{J} /(\mathrm{kg} \mathrm{K})]$

Figure 3: T-S diagram for Bell Coleman Cycle 
Reference [6] reported in reverse-bootstrap air cycle refrigeration system driven by powered turbine similar trend being that this time it is for heat pump having inlet air temperature at $180 \mathrm{~K}$ and outlet air temperature at $320 \mathrm{~K}$.

T-S diagram for Bootstrap air cycle refrigeration system is shown in figure 5 below. This was done at the critical conditions of $140.65^{\circ} \mathrm{C}$ and 37.7436 bar and showed an elaborate view that included enthalpy in $\mathrm{kJ} / \mathrm{kg}$ and specific volume in $\mathrm{m}^{3} / \mathrm{kg}$. At its ACRS temperature of $-206.8^{\circ} \mathrm{C}$, the entropy extended from -300 to $3000 \mathrm{~J} / \mathrm{kgK}$. It also indicated enthalpy state from $90 \mathrm{~kJ} / \mathrm{kg}$ and specific volume from 0.005 to $1.0 \mathrm{~m}^{3} / \mathrm{kg}$. The enthalpy reflects similar range in its pressure-enthalpy plot.

\section{B. CCD Analysis and Optimization of Coefficient of Performance and Entropy in ACRS}

The COP depends mostly on the results if there is significant variation for combination of work of compression and refrigerating effect while entropy depends mostly on air temperature. The empirical relationship between the responses COP and entropy and the three variables in coded values obtained by using the statistical package Design-Expert 11 version for determining the levels of factors which gives optimum COP and entropy was given by the (13) and (14). The quadratic regression equations that fitted the data for all the new modeled thermal properties are illustrated also in (15) and (16).

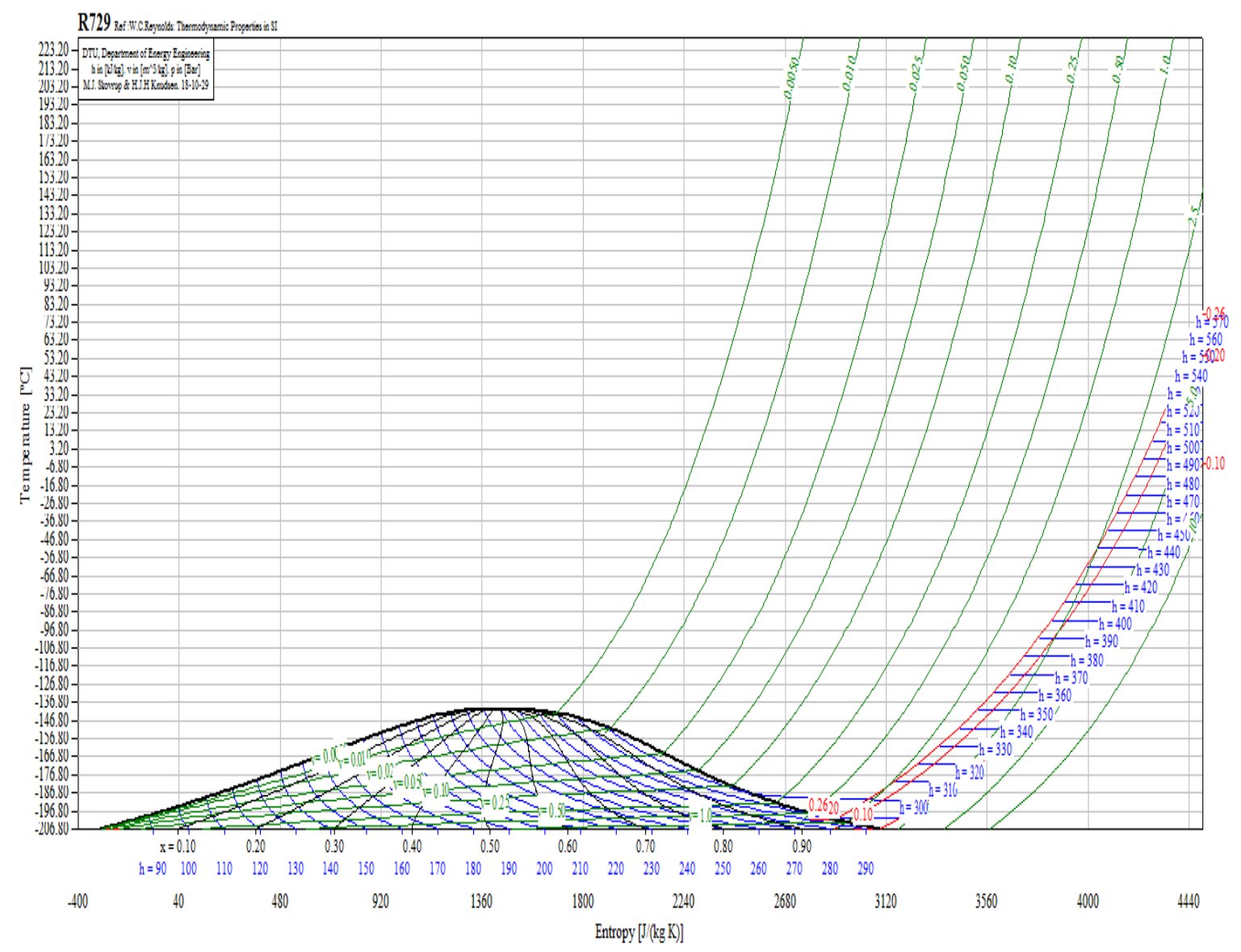

Figure 4: T-S diagram for Bootstrap Air Cycle Refrigeration System

$Z=+0.342995+0.000373 A+0.012391 B-0.004918 C-3.98720 \mathrm{E}^{-20} \mathrm{AB}+9.91693 \mathrm{E}^{-21} \mathrm{AC}$

$-0.000037 \mathrm{BC}-8.65167 \mathrm{E}^{-07} \mathrm{~A}^{2}-8.56618 \mathrm{E}^{-07} \mathrm{~B}^{2}+0.000015 \mathrm{C}^{2}$

$\mathrm{S}=+0.299235+0.021143 \mathrm{~A}+0.000391 \mathrm{~B}-0.000018 \mathrm{C}-0.00720 \mathrm{AB}+0.021693 \mathrm{AC}$

$-3.214037 \mathrm{E}^{-21} \mathrm{BC}-0.0005167 \mathrm{~A}^{2}-8.56618 \mathrm{E}^{-07} \mathrm{~B}^{2}-1.023015 \mathrm{E}^{-07} \mathrm{C}^{2}$

The accuracy and adequacy of the above proposed model was tested using the Design Expert sequential model sum of squares and the model test statistics. From the sequential test, it can be seen that the model F-values is 9415.8. The Model F-value of 9415.80 implies the model is significant and there is only a $0.01 \%$ chance that an F-value this large could occur due to noise.

P-values less than 0.0500 indicate model terms are significant because values greater than 0.1000 indicate the model terms are not significant.. In this case B, C, BC, $\mathrm{C}^{2}$ are significant model terms. Table 4.10 shows the regression coefficients and adjusted regression coefficient which are in close agreement with their respective predicted values. The Predicted $\mathrm{R}^{2}$ of 0.9990 is in reasonable agreement with the Adjusted $\mathrm{R}^{2}$ of 0.9998 ; i.e. the difference is less than 0.2 . The same trend is noticed for entropy 
when considered as response too. Adeq Precision measures the signal to noise ratio. A ratio greater than 4 is desirable. The ratio of 343.503 indicates an adequate signal; therefore the model can be used to navigate the design space.

The coefficient of variance $(\mathrm{CV})$ is the ratio of the standard error of the estimate to the mean value of the observed response and is considered reproducible once it is not greater than $10 \%$. In this work, the CV obtained for the entire model is $0.369 \%$ for COP and $0.443 \%$ for entropy.

\begin{tabular}{|c|c|c|c|c|c|}
\hline Source & Sum of Squares & df & Mean Square & F-value & p-value \\
\hline Block & 0.0000 & 1 & 0.0000 & & \\
\hline Model & 0.5041 & 9 & 0.0560 & 9415.80 & $<0.0001$ \\
\hline A-Air Temperature & 0.0000 & 1 & 0.0000 & 0.0000 & 1.0000 \\
\hline B-Refrigerating Effect & 0.4660 & 1 & 0.4660 & 78337.65 & $<0.0001$ \\
\hline C-Work of Compression & 0.0362 & 1 & 0.0362 & 6078.60 & $<0.0001$ \\
\hline $\mathrm{AB}$ & 0.0000 & 1 & 0.0000 & 0.0000 & 1.0000 \\
\hline $\mathrm{AC}$ & 0.0000 & 1 & 0.0000 & 0.0000 & 1.0000 \\
\hline $\mathrm{BC}$ & 0.0018 & 1 & 0.0018 & 302.59 & $<0.0001$ \\
\hline $\mathrm{A}^{2}$ & $8.889 \mathrm{E}-06$ & 1 & $8.889 \mathrm{E}-06$ & 1.49 & 0.2526 \\
\hline $\mathrm{B}^{2}$ & $8.889 \mathrm{E}-06$ & 1 & $8.889 \mathrm{E}-06$ & 1.49 & 0.2526 \\
\hline $\mathrm{C}^{2}$ & 0.0001 & 1 & 0.0001 & 18.30 & 0.0021 \\
\hline Residual & 0.0001 & 9 & $5.949 \mathrm{E}-06$ & & \\
\hline Lack of Fit & 0.0001 & 5 & 0.000025 & 4.22 & 0.02555 \\
\hline Cor Total & 0.5042 & 19 & & & \\
\hline
\end{tabular}

The analysis of variance (ANOVA) results for the model terms are given in Tables 1. Analysis of variance (ANOVA) was applied for estimating the significance of the model at 5\% significance level and a model is considered significant if the $\mathrm{p}$-value (significance probability value) is less than 0.05 . From the p-values presented in Table 2, it can be stated that B, C, BC, $\mathrm{C}^{2}$ are significant model term for COP. Due to these, the equation of the models is reduced thus:

$\mathrm{Z}=+0.342995+0.012391 \mathrm{~B}-0.004918 \mathrm{C}-0.000037 \mathrm{BC}+0.000015 \mathrm{C}^{2}$

$\mathrm{S}=+0.299235+0.021143 \mathrm{~A}-0.00720 \mathrm{AB}+0.021693 \mathrm{AC}-0.0005167 \mathrm{~A}^{2}$

In this study, the calculated data were also analyzed to check the correlation between the actual and predicted response. It can be seen from the figures that the data points on the plot were reasonably distributed near to the straight line, indicating a good relationship between the actual and predicted values of the COP and entropy separately. The underlying assumptions of the above analysis were appropriate. The result also suggests that the selected quadratic model was adequate in predicting the dependent variable or response variables for the data.

\section{Design-Expert ${ }^{\circledR}$ Software Trial Version}

\section{COP}

Color points by value of

COP:

0.35

0.97

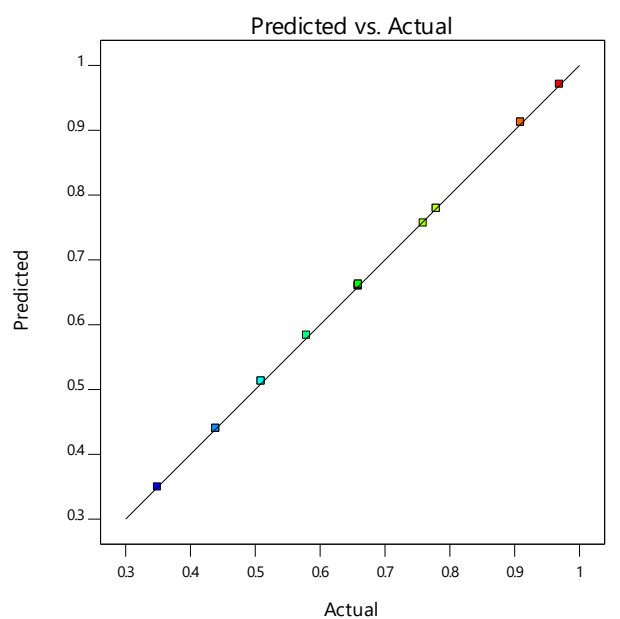

Figure 5: Predicted values versus the actual values for $\mathrm{COP}$ with respect to the independent variables 

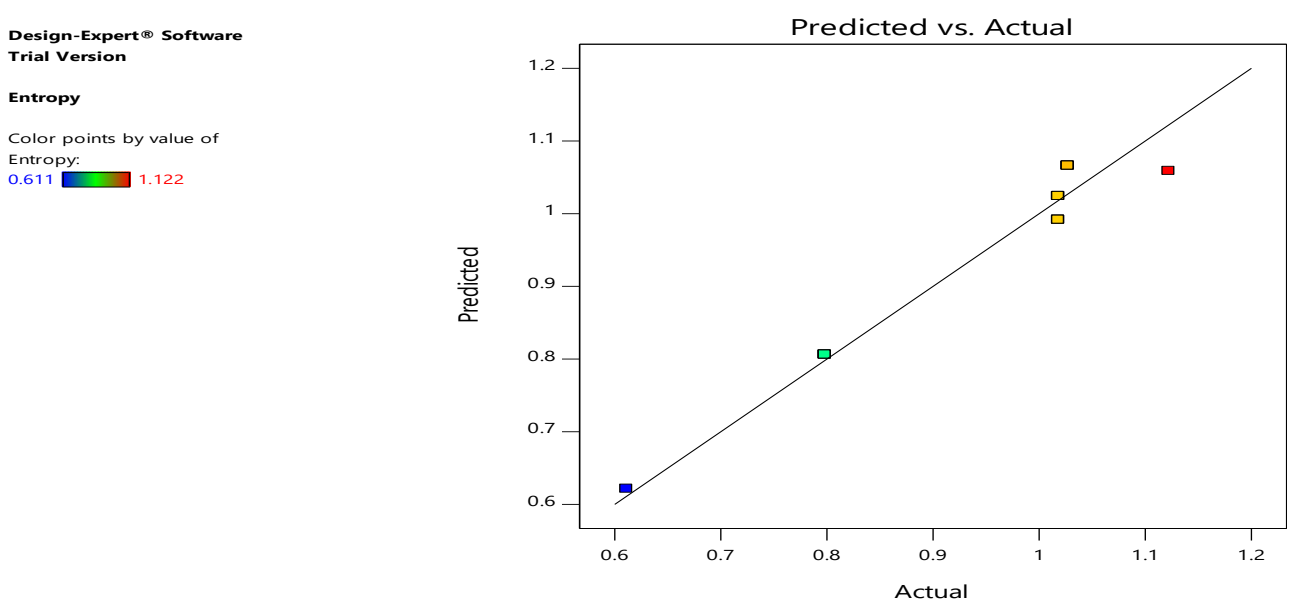

Figure 6: Predicted values versus the actual values for Entropy with respect to the independent variables

COP $0.35 \stackrel{0.97}{\square}$

$\mathrm{X} 1=\mathrm{A}:$ Air Temperature $\mathrm{X} 2=\mathrm{B}:$ Refrigerating Effect

Actual Factor

C: Work of Compression $=164.71$

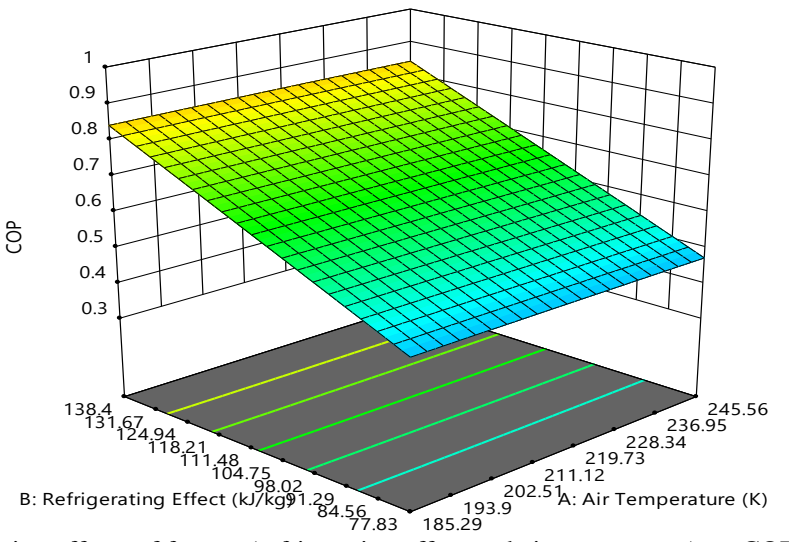

Figure 7: RSM 3D plot indicating interaction effects of factors (refrigerating effect and air temperature) on COP
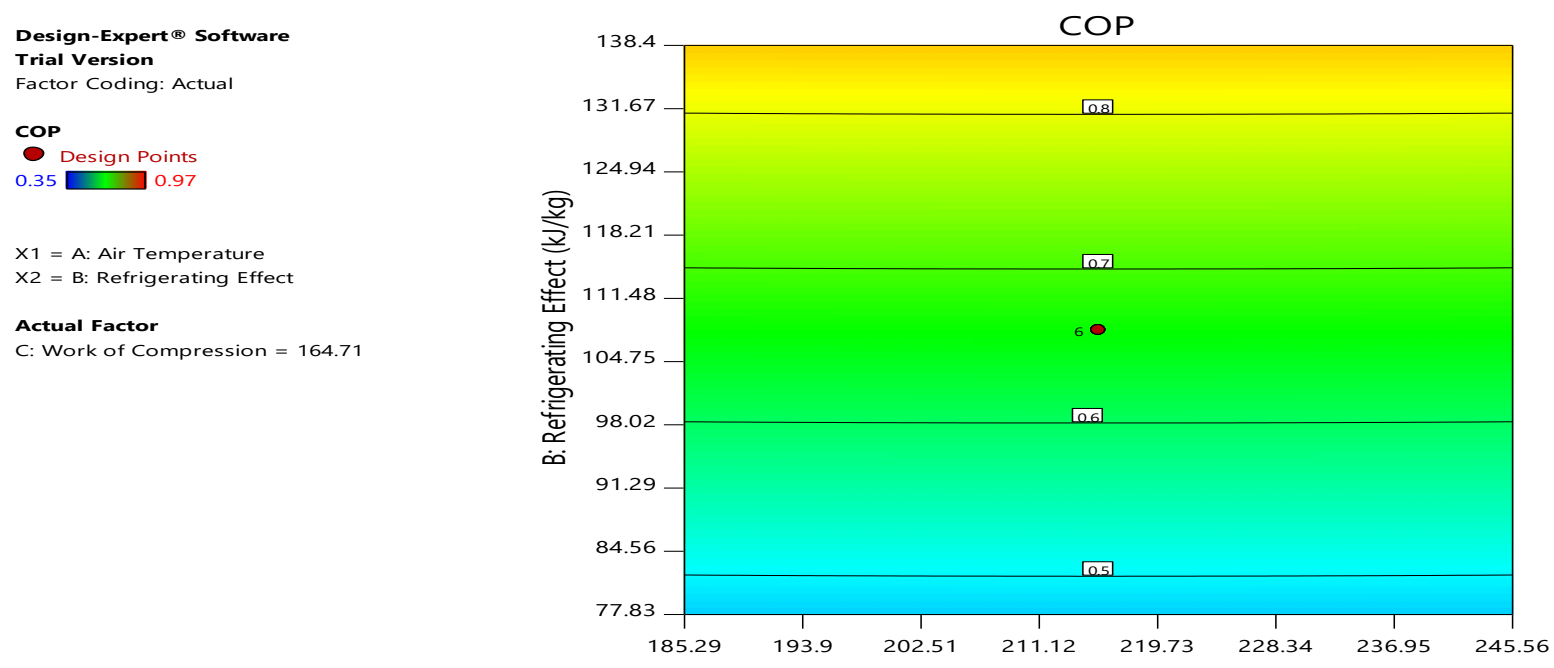

A: Air Temperature (K)

Figure 8: Response surface contour plot indicating interaction effects of factors (refrigerating effect and air temperature) on COP. 


\section{Entropy (kJ/kgK)}

Design points below predicted value $0.611 \square 1.122$

$\mathrm{X} 1=\mathrm{A}:$ Air Temperature

$\mathrm{X} 2=\mathrm{B}$ : Refrigerating Effect

\section{Actual Factor}

C: Work of Compression $=164.71$

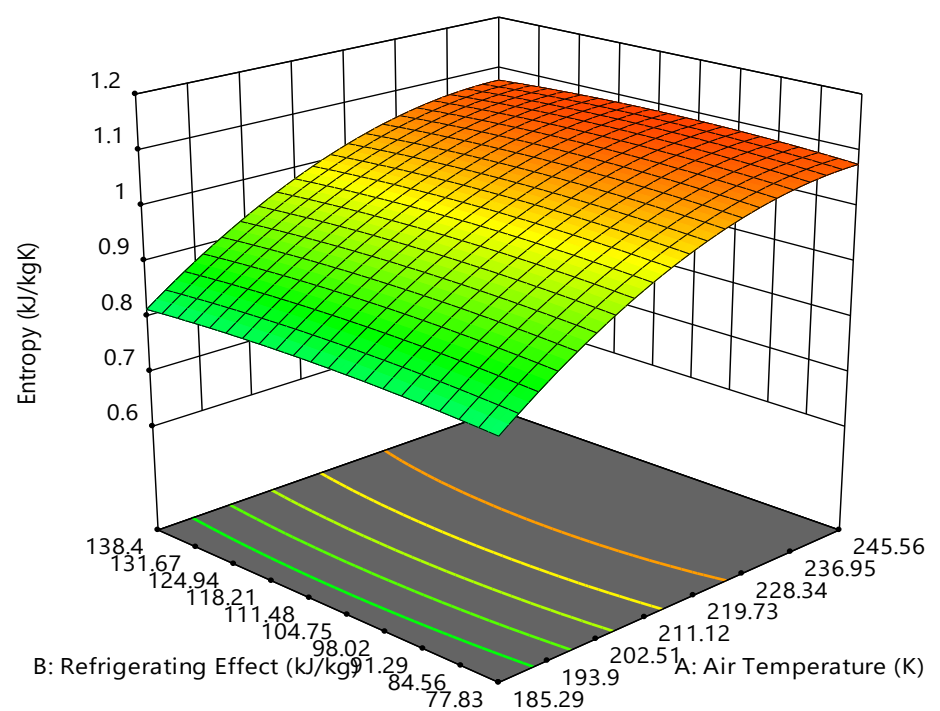

Figure 9: RSM 3D plot indicating interaction effects of factors (refrigerating effect and air temperature) on Entropy.
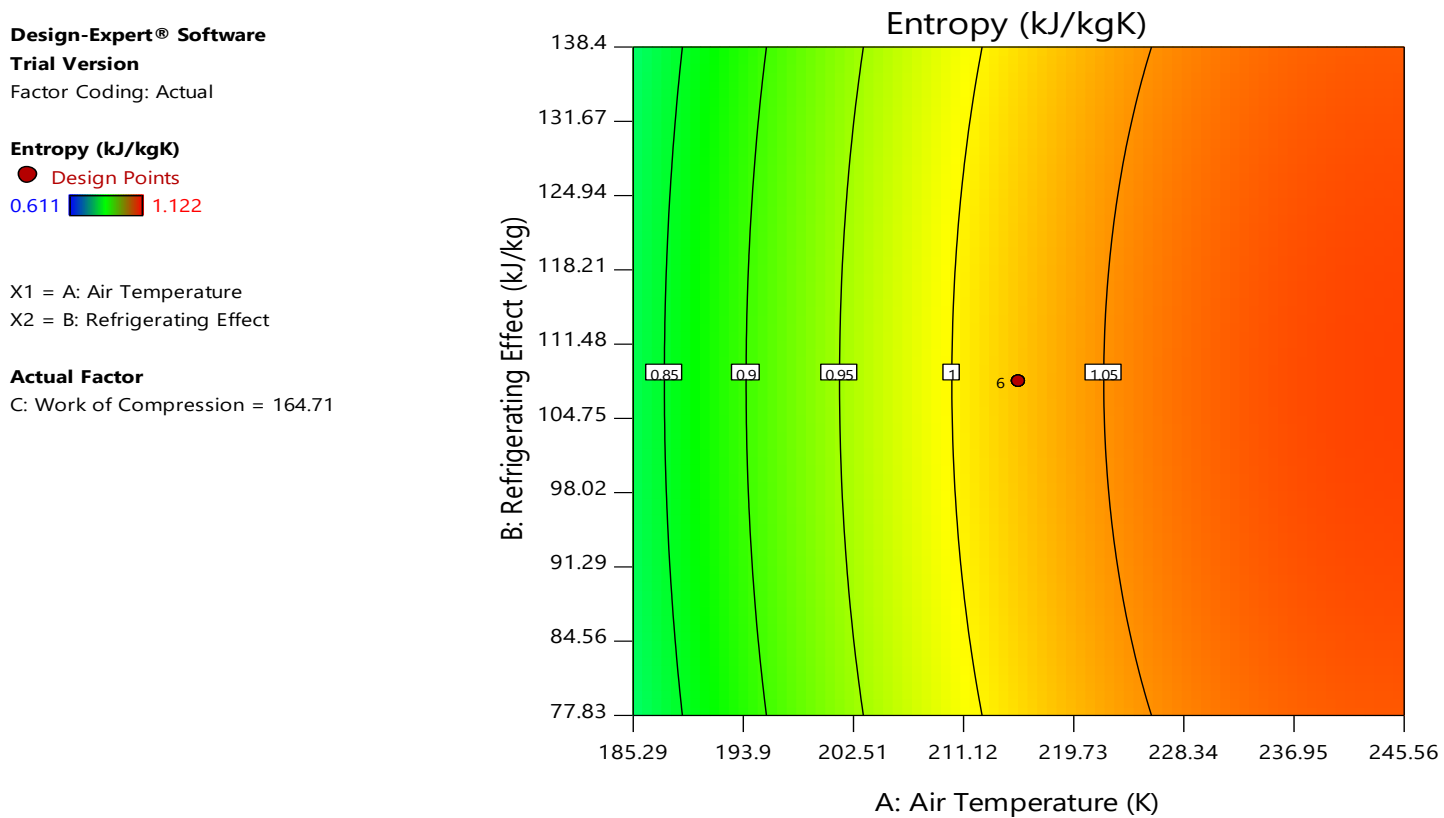

Figure 10: Response surface contour plot indicating interaction effects of factors (refrigerating effect and air temperature) on Entropy.

It can be seen that the error between the experimental and predicted is less than $1 \%$, therefore it can be concluded that the generated model has sufficient accuracy to predict the response.

Table 3: Optimal regression coefficient of COP and Entropy with respect to the independent variables

\begin{tabular}{|c|c|c|c|c|c|c|c|c|c|c|c|}
\hline & $\begin{array}{c}\text { Intercep } \\
\mathbf{t}\end{array}$ & Block [1] & A & B & C & AB & $\mathrm{AC}$ & BC & $\mathbf{A}^{2}$ & $\mathbf{B}^{2}$ & $\mathrm{C}^{2}$ \\
\hline $\begin{array}{r}\text { Entrop } \\
\mathbf{y}\end{array}$ & 1.02447 & 0.0180123 & 0.13 & $\begin{array}{r}2.19168 \mathrm{E} \\
-17\end{array}$ & $\begin{array}{r}7.54624 \mathrm{E} \\
-17\end{array}$ & $\begin{array}{r}- \\
9.92733 \mathrm{E} \\
-17\end{array}$ & $\begin{array}{r}-- \\
9.08243 \mathrm{E} \\
-17\end{array}$ & $\begin{array}{r}1.16238 \mathrm{E} \\
-16\end{array}$ & -0.0651048 & -0.0115415 & 0.0115415 \\
\hline $\begin{array}{r}\text { p- } \\
\text { values }\end{array}$ & & & $<0.0001$ & 1.0000 & 1.0000 & 1.0000 & 1.0000 & 1.0000 & $<0.0001$ & 0.1518 & 0.1518 \\
\hline COP & 0.66044 & $\begin{array}{r}- \\
0.0012261 \\
7\end{array}$ & $\begin{array}{r}- \\
2.52439 \mathrm{E} \\
-17\end{array}$ & 0.184721 & $\begin{array}{r}- \\
0.051455 \\
7\end{array}$ & $\begin{array}{r}3.76436 \mathrm{E} \\
-17\end{array}$ & $\begin{array}{r}1.97326 \mathrm{E} \\
-18\end{array}$ & -0.015 & $\begin{array}{r}- \\
0.00078567 \\
4\end{array}$ & $\begin{array}{r}0.00078567 \\
4\end{array}$ & $\begin{array}{r}0.0027498 \\
6\end{array}$ \\
\hline $\begin{array}{r}\text { p- } \\
\text { values }\end{array}$ & & & 1.0000 & $\begin{array}{l}<0.0001 \\
\end{array}$ & $<0.0001$ & 1.0000 & 1.0000 & $<0.0001$ & 0.2526 & 0.2526 & 0.0021 \\
\hline
\end{tabular}



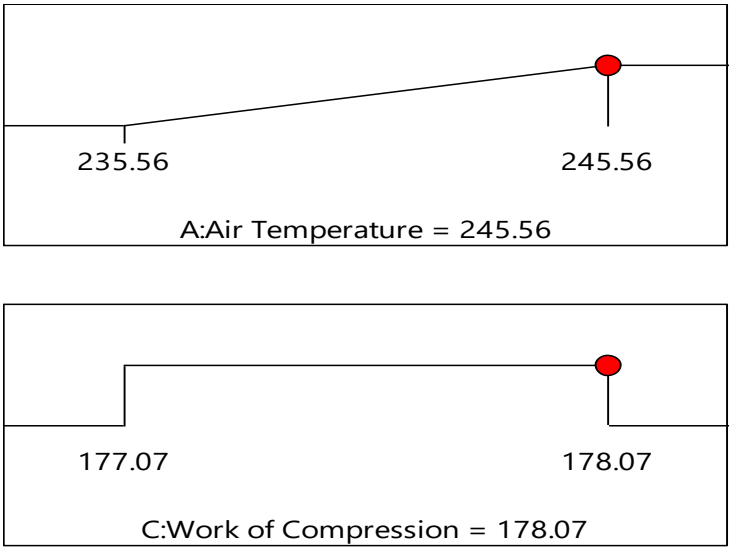
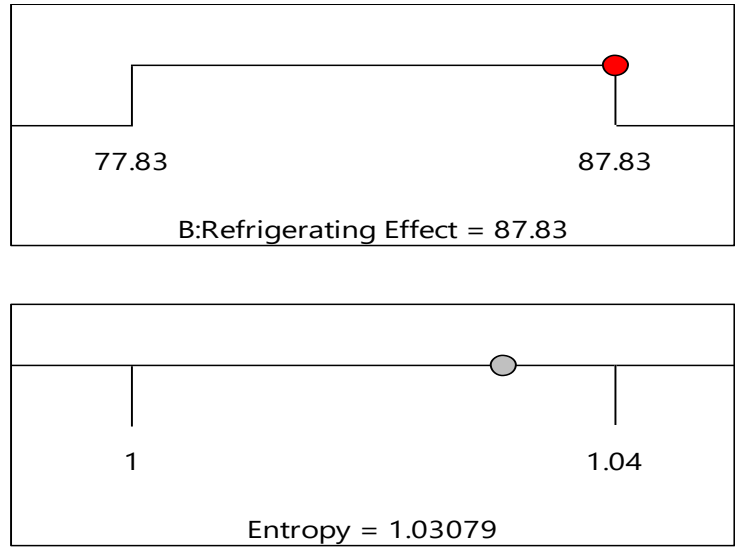

\author{
Desirability $=1.000$ \\ Solution 1 out of 100 \\ Figure 11: The desirability range of the independent variables
}

\title{
IV. CONCLUSION
}

The results of the study showed the level of effectiveness of the different ACRSs analyzed in this work considering Nigerian environment. The condition and thermodynamic properties of air used as a case study was gotten from catalogs of the airline operatives at AIIA based on year round mean conditions at $45^{\circ}$ latitude and varies with the time of the year and the weather patterns.

However, to show the relevance of this work, it corresponds with the aim and objectives of the International Refrigeration and Air conditioning conference held at Purdue July 12 to 15, 2010 about aircraft's cabin. They noted that the cabin temperature would rise up to $50^{\circ} \mathrm{C}(323 \mathrm{~K})$ within some 15 windows, $11 \%$ electrical load of lightening of air craft that flies at about $10 \mathrm{~km}$ and $12 \mathrm{~km}$. This has a whole lot to do with scope and limitation of this research. From the foregoing, Bootstrap air refrigeration cycle is the efficient ACRS for this aircraft's cabin. This is because Bootstrap air refrigeration system produced a higher COP than other systems. Moreover, it has been long recognized that other air cycle refrigeration systems yield a close COP and Refrigerating effect. COP is one of the responses and refrigerating effect is one of the factors used in optimization of the thermal properties of ACRS using response surface methodology in this work. The COP, RE, $\mathrm{W}_{\mathrm{c}}$ and $\mathrm{T}_{\mathrm{cb}}$ of the different Air cycle refrigeration system has been successfully identified and optimized through response surface methodology in this research which left Bootstrap air cycle refrigeration system the better in terms of COP and RE where as Reduced Ambient ACRS is better in $\mathrm{T}_{\mathrm{cb}}$.

\section{REFERENCES}

[1] P. Liping, Q. Yue, L. Dong, and L. Meng, 'Thermal comfort assessment in civil aircraft cabins. Chinese Journal of Aeronautics. Beihang University'. Volume 27, Issue 2, Pages 210-216, April 2014.

[2] A. Ujam, 'Refrigeration and air conditioning' (B. Eng, M. Eng, Eng Mnse, MNSE, MASME) 2009.

[3] L. Shengjun, Z. Zhenying, and T. Lili, 'Thermodynamic analysis of the actual air cycle refrigeration system'. Hebei United University, Tangshan 063009, China. Earthquake engineering research center of Hebei Province, Tangshan 063009, China. Tangshan College, Tangshan 063000, China, 2011.

[4] U. Shet, T. Sundararajan, and J. Mallikarjuna, 'Note on Refrigeration cycle'. Indian institute of Technology Madras, 2012.

[5] P. Desai, 'Refrigeration and Air conditioning'. Watana press 01435 Khana publishers. 2-B, Nath Market, Nai Sarak, New Delhi-11007 (India), pp. 18, 2004.

[6] Z. Deng, (2009) 'Research on Reverse-bootstrap Air Cycle Refrigeration System Driven by Powered Turbine'. Master's thesis, Nanjing University of Aeronautics and Astronautics, 2009. 